\title{
Brand-new Biomass-based Vinyl Polymers from 5-Hydroxymethylfurfural
}

\author{
By Naoki YOSHIDA, ${ }^{1}$ Natsuki KASUYA, ${ }^{2, *}$ Naoki HAGA, ${ }^{2}$ and Kiyoharu FUKUDA ${ }^{2}$
}

The synthesis of novel biomass-based vinyl polymers from 5-(hydroxymethyl)furfural (HMF) as the starting material was accomplished. HMF or its methylated derivative, 5-(methoxymethyl)furfural was efficiently converted to its vinyl derivative by the Wittig reaction in a solid-liquid phase transfer process, followed by free radical polymerization in a bulk polymerization process. The structures of the obtained vinyl monomers and resulting polymers were confirmed by using NMR spectroscopy, including ${ }^{1} \mathrm{H}$ NMR, ${ }^{13} \mathrm{C}$ NMR, C-H COSY, and C-H COLOC. Moreover, the resulting polymers were subjected to GPC, thermogravimetric analysis (TGA) and differential scanning calorimetry (DSC), and the polymer from 5methoxymethyl-2-vinylfuran exhibited much better heat resistance than the corresponding polymer without methoxy group. KEY WORDS: Biomass-based Polymer / 5-(Hydroxymethyl)furfural / Radical Polymerization / Heat Resistance /

With global intent increasing to diminish our dependence on petroleum, there has been growing interests in replacing petroleum-derived raw materials with ones that are biomassderived. 5-(Hydroxymethyl)furfural (HMF) is expected to become one of these biomass-derived raw materials for supplying fuel and/or feedstock into various chemicals and polymers. ${ }^{1,2}$ Since the dehydration reaction of six-carbon sugar molecules such as glucose and fructose produces HMF, much work has been done in an attempt to convert glucose and fructose efficiently and inexpensively into $\mathrm{HMF} .{ }^{3-8}$ Although there are still many problems to be overcome, such as low conversion, selectivity to $\mathrm{HMF}$, and huge energy requirements for purification, the technologies to produce HMF from carbohydrates have been progressing step by step. Zhang et al. (2007) produced HMF from glucose at a high yield of $70 \%$, and showed the prospects of converting cellulose, the most abundant renewable resource on earth, to HMF with a high yield that could be achieved in the near future. ${ }^{8}$

Since HMF is a furan derivative that has two functional groups at the reverse sides on its furan ring to each other, i.e., at the C-2 and C-5 positions, it can easily be converted to various 2,5-disubstituted furan derivatives such as 2,5-furandicarboxylic acid (FDCA), 2,5-bis(hydroxymethyl)furan, and 2,5bis(aminomethyl)furan, ${ }^{9-11}$ leading these to become potential building blocks for step-growth polymers such as polyesters, polyamides, and polyurethanes. In fact, there has been much previous work on step-growth polymers from HMF as the starting material..$^{9,10,12-19}$

However, as far as we know, no studies have yet been reported on the synthesis of addition polymers from HMF as the starting material. When we can develop the addition polymers such as vinyl polymers inexpensively from biomassderived HMF, these could become one of the substitutes for "commodity polymers," such as polyethylene, poly(vinyl chloride), and polystyrene, which are used today in large quantities throughout the world. In particular, since furan derivatives are flame retardant and heat resistant, ${ }^{20}$ addition polymers from HMF could be expected to retain these properties even after the polymerization and have similar properties to polystyrene. They could even be used as a substitute for it. In the study reported here, we attempted to synthesize brand-new vinyl polymers derived from HMF, converting the formyl group in HMF or its methylated derivative into a vinyl group with the Wittig reaction, and polymerizing the molecules (monomers) through a free radical addition reaction. The characterization of the resulting polymers including their thermal behaviors is also reported in this paper.

\section{EXPERIMENTAL}

\section{Materials}

The HMF was purchased from Aldrich Chemical Co, and all the other reagents and solvents including methyltriphenylphosphonium bromide were purchased from Wako Pure Chemical Industries. The reagents and solvents were used as received except for 2,2'-azobis(isobutyronitrile) (AIBN), which was purified by recrystallization from methanol.

\section{Measurements}

${ }^{1} \mathrm{H}$ NMR, ${ }^{13} \mathrm{C}$ NMR, C-H COSY and C-H COLOC spectra were recorded on a JEOL ALPHA-600 (600 MHz) spectrometer.

The number-average molecular weights $\left(M_{\mathrm{n}}\right)$ and molecular weight distributions $\left(M_{\mathrm{w}} / M_{\mathrm{n}}\right)$ were estimated by gel permeation chromatography (GPC) with a JASCO CO-2065 Plus instrument and a JASCO RI-2031 Plus detector equipped with a polystyrene gel column (TOSOH TSKgel $\mathrm{G} 2500 \mathrm{H}_{\mathrm{XL}}$ and $\mathrm{G} 4000 \mathrm{H}_{\mathrm{XL}}$ ). The mobile phase, pyridine, was eluted at a rate of $0.5 \mathrm{~mL} \mathrm{~min}^{-1}$ and the calibration was done by using the polystyrene (PS) standard.

\footnotetext{
${ }^{1}$ Department of Environmental and Natural Resource Sciences, Tokyo University of Agriculture and Technology, Saiwai-cho, Fuchu 183-8509, Japan ${ }^{2}$ Institute of Symbiotic Science and Technology, Tokyo University of Agriculture and Technology, Saiwai-cho, Fuchu 183-8509, Japan

*To whom correspondence should be addressed (Tel: +81-42-367-5843, Fax: +81-42-334-5700, E-mail: kasuya@ @cc.tuat.ac.jp).
} 

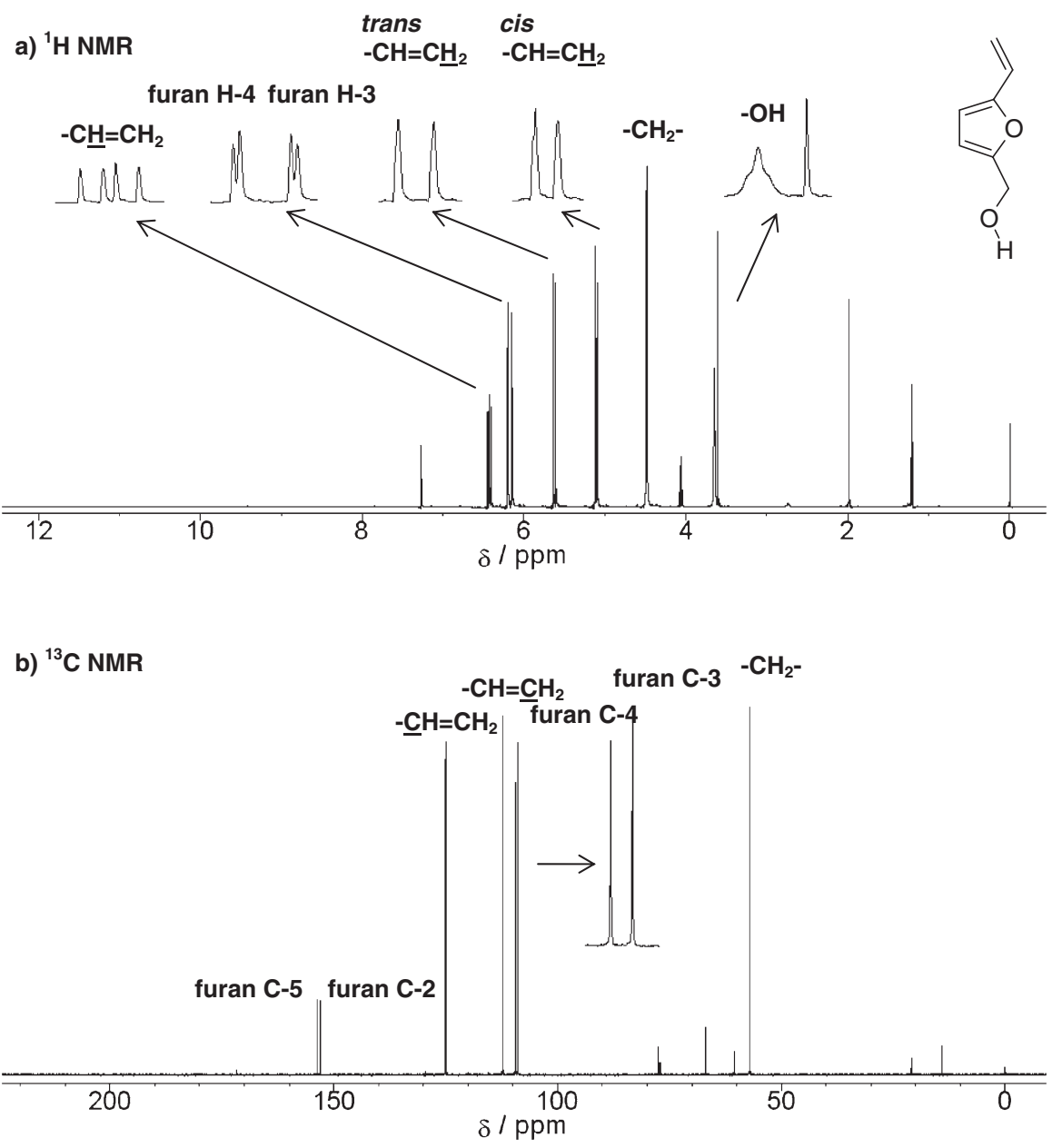

Figure 1. (a) ${ }^{1} \mathrm{H}$ NMR and (b) ${ }^{13} \mathrm{C}$ NMR spectra (chloroform-d, $600 \mathrm{MHz}$ ) of HMVF.

The thermogravimetric analysis (TGA) was performed on a SHIMADZU DTG-60 under a helium gas atmosphere from room temperature to $600^{\circ} \mathrm{C}$ at a heating rate of $10^{\circ} \mathrm{C} \mathrm{min}^{-1}$, and the differential scanning calorimetry (DSC) was also used to measure the thermal transitions of the polymers on a SHIMADZU DSC-50 under a helium gas atmosphere from room temperature to $600{ }^{\circ} \mathrm{C}$ at a heating rate of $10^{\circ} \mathrm{C} \mathrm{min}^{-1}$.

\section{Monomer Preparation}

5-(Methoxymethyl)furfural (MMF) was prepared from HMF according to previous work. ${ }^{21}$ A mixture of $\mathrm{HMF}(0.455 \mathrm{~g}$, $3.61 \mathrm{mmol})$, methanol $(40 \mathrm{~mL})$, and $p$-toluene sulphonic acid $(0.010 \mathrm{~g}, 0.05 \mathrm{mmol})$ was refluxed for $10 \mathrm{~h}$. After methanol was evaporated under reduced pressure, the crude product was heated with deionized water $(30 \mathrm{~mL})$ at $90^{\circ} \mathrm{C}$ with agitation for $1 \mathrm{~h}$, and extracted with diethyl ether with the addition of salt $(\mathrm{NaCl})$ to the water phase. The organic phase was washed with a saturated aqueous solution of sodium chloride containing some sodium bicarbonate and dried over sodium sulfate. After diethyl ether was removed by evaporation, the residue was dissolved in hexane. The solution was washed with a saturated solution of aqueous sodium chloride, and dried over sodium sulfate. Finally, the hexane was evaporated under reduced pressure to derive a yellow and transparent liquid. The yield was $0.222 \mathrm{~g}(43.9 \%)$. ${ }^{1} \mathrm{H}$ NMR ( $\delta$ in $\mathrm{ppm}$ from TMS in $\left.\mathrm{CDCl}_{3}\right): 3.31\left(\mathrm{~s}, 3 \mathrm{H},-\mathrm{CH}_{3}\right), 4.39\left(\mathrm{~s}, 2 \mathrm{H},-\mathrm{CH}_{2}-\right), 6.45(\mathrm{~d}, 1 \mathrm{H}$, furan $\mathrm{H}-4), 7.14(\mathrm{~d}, 1 \mathrm{H}$, furan $\mathrm{H}-3), 9.51(\mathrm{~s}, 1 \mathrm{H},-\mathrm{CHO})$. ${ }^{13} \mathrm{C}$ NMR ( $\delta$ in ppm from TMS in $\left.\mathrm{CDCl}_{3}\right): 58.68\left(-\mathrm{CH}_{3}\right), 66.57$ (- $\mathrm{CH}_{2}-$ ), 111.34 (furan C-4), 122.16 (furan C-3), 152.72 (furan C-5), 158.37 (furan $\mathrm{C}-2), 177.80$ (-ㄷHO).

5-Hydroxymethyl-2-vinylfuran (HMVF) was prepared according to a method ${ }^{20}$ previously reported for synthesizing 2-vinylfuran from furfural. A mixture of HMF $(0.464 \mathrm{~g}$, $3.68 \mathrm{mmol})$, methyltriphenylphosphonium bromide $(1.480 \mathrm{~g}$, $4.14 \mathrm{mmol})$, potassium carbonate $(2.598 \mathrm{~g}, 18.82 \mathrm{mmol})$, deionized water $(0.07 \mathrm{~mL}, 3.89 \mathrm{mmol})$, and 1,4-dioxane $(30 \mathrm{~mL})$ was stirred at $90^{\circ} \mathrm{C}$ for $3 \mathrm{~h}$. The reaction mixture was filtered and the solvent was removed by evaporation. The residue was dissolved in diethyl ether and the solution was washed with deionized water five times, followed by purification with silica gel column chromatography $($ EtOAc/Hexane $=1 / 2)$. The product was obtained as a transparent and slightly yellow liquid. The yield was $0.305 \mathrm{~g}(66.7 \%) .{ }^{1} \mathrm{H}$ NMR ( $\delta$ in ppm from TMS in $\mathrm{CDCl}_{3}$ ) (Figure 1): 3.65 (br s, $\left.1 \mathrm{H},-\mathrm{OH}\right), 4.51(\mathrm{~s}, 2 \mathrm{H}$, $\left.-\underline{\mathrm{CH}}_{2}-\right), 5.11\left(\mathrm{~d}, 1 \mathrm{H}\right.$, cis $\left.-\mathrm{CH}=\mathrm{CH}_{2}\right), 5.63$ (d, $1 \mathrm{H}$, trans $\left.-\mathrm{CH}=\mathrm{CH}_{2}\right), 6.16(\mathrm{~d}, 1 \mathrm{H}$, furan $\mathrm{H}-3), \overline{6} .21(\mathrm{~d}, 1 \mathrm{H}$, furan $\mathrm{H}-4)$, 

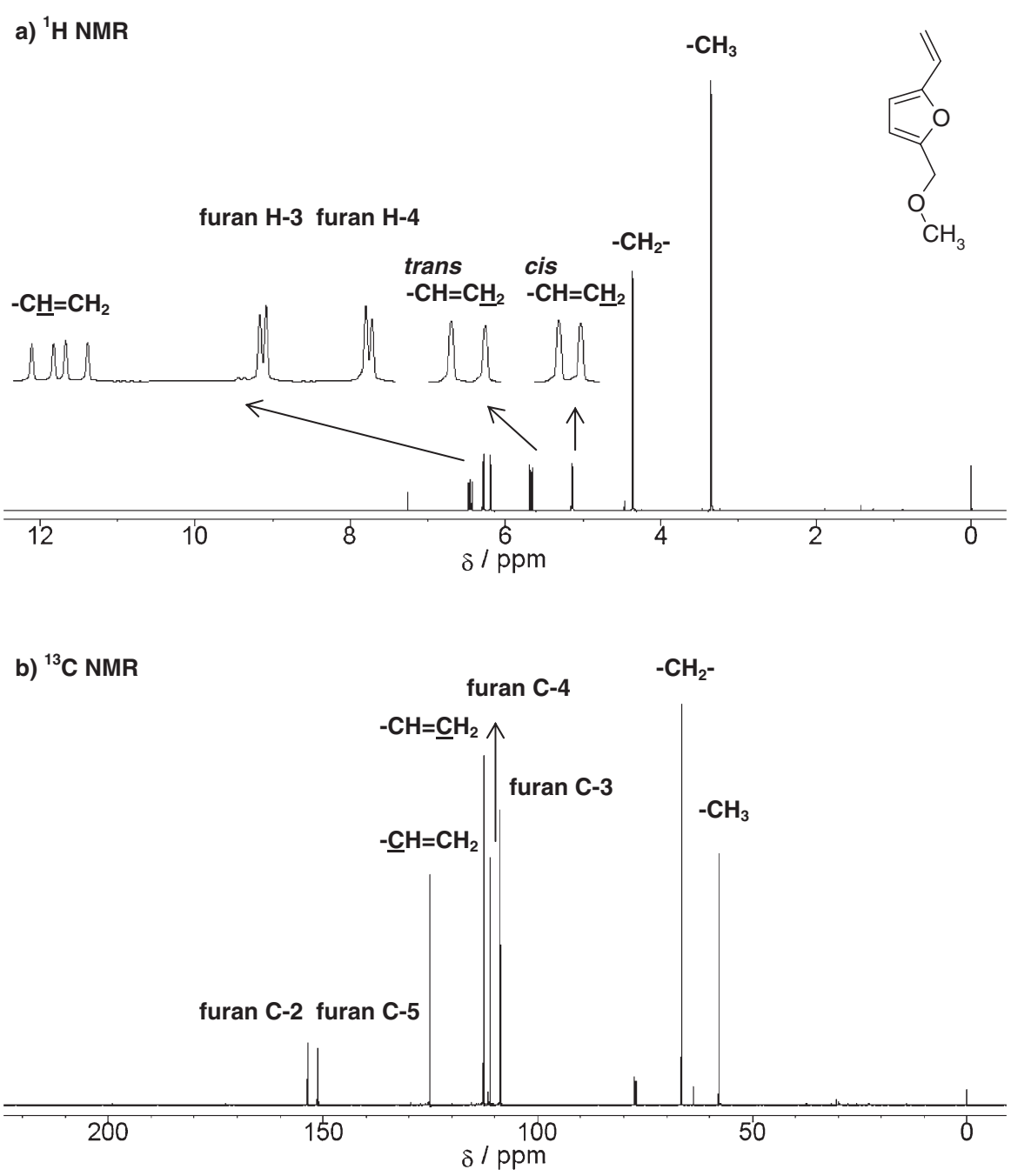

Figure 2. (a) ${ }^{1} \mathrm{H}$ NMR and (b) ${ }^{13} \mathrm{C}$ NMR spectra (chloroform-d, $600 \mathrm{MHz}$ ) of MMVF.

$6.43\left(\mathrm{~m}, 1 \mathrm{H},-\mathrm{CH}=\mathrm{CH}_{2}\right) .{ }^{13} \mathrm{C}$ NMR $(\delta$ in ppm from TMS in $\mathrm{CDCl}_{3}$ ): 57.24 (- $\left.\mathrm{CH}_{2}-\right), 109.05$ (furan $\mathrm{C}-3$ ), 109.35 (furan $\left.\mathrm{C}-4\right)$, $112.18\left(-\mathrm{CH}=\underline{\mathrm{CH}}_{2}\right), 125.26\left(-\underline{\mathrm{CH}}=\mathrm{CH}_{2}\right), 153.14$ (furan $\left.\mathrm{C}-2\right)$, 154.34 (furan C-5).

5-Methoxymethyl-2-vinylfuran (MMVF) was prepared according to the same method as that for HMVF, using MMF $(0.276 \mathrm{~g}, 1.97 \mathrm{mmol})$ as the starting substance instead of HMF. Purification was performed by silica gel column chromatography $($ EtOAc/Hexane $=1 / 8)$ and a yellow liquid was obtained. The yield was $0.112 \mathrm{~g}(41.0 \%) .{ }^{1} \mathrm{H}$ NMR $(\delta$ in ppm from TMS in $\mathrm{CDCl}_{3}$ ) (Figure 2): 3.35 (s, 3H, $-\mathrm{CH}_{3}$ ), 4.36 (s, $\left.2 \mathrm{H},-\underline{\mathrm{C}}_{2}-\right), 5.13\left(\mathrm{~d}, 1 \mathrm{H}\right.$, cis $\left.-\mathrm{CH}=\mathrm{CH}_{2}\right), 5.66(\mathrm{~d}, 1 \mathrm{H}$, trans $\left.-\mathrm{CH}=\mathrm{CH}_{2}\right), 6.19(\mathrm{~d}, 1 \mathrm{H}$, furan $\mathrm{H}-4), 6.28(\mathrm{~d}, 1 \mathrm{H}$, furan $\mathrm{H}-3)$, $6.45\left(\mathrm{~m}, \overline{1} \mathrm{H},-\mathrm{C} \underline{\mathrm{H}}=\mathrm{CH}_{2}\right) .{ }^{13} \mathrm{C}$ NMR ( $\delta$ in ppm from TMS in $\left.\mathrm{CDCl}_{3}\right): 57.90\left(-\mathrm{CH}_{3}\right), 66.55\left(-\mathrm{CH}_{2}\right), 108.74$ (furan $\left.\mathrm{C}-3\right)$, 111.09 (furan $\mathrm{C}-4), 112.66\left(-\mathrm{CH}=\underline{\mathrm{CH}}_{2}\right), 125.11\left(-\underline{\mathrm{CH}}=\mathrm{CH}_{2}\right)$, 151.37 (furan C-5), 153.60 (furan C-2).

\section{Polymerization}

Poly(5-hydroxymethyl-2-vinylfuran) (PHMVF) was obtained according to the method described below. A mixture of HMVF (0.164 g, $1.32 \mathrm{mmol})$ and AIBN (0.009 g, $0.05 \mathrm{mmol})$ was stirred at $70^{\circ} \mathrm{C}$ under a nitrogen atmosphere for $10 \mathrm{~h}$. After methanol was added to the reaction mixture to quench polymerization, the mixture was stirred at room temperature for $30 \mathrm{~min}$ and methanol was removed by evaporation. The crude product was washed with hexane three times to remove the initiator and monomer, followed by drying at $40^{\circ} \mathrm{C}$ under reduced pressure for a week. Then, a yellow solid was obtained and its yield was $0.086 \mathrm{~g}(52.3 \%)$. ${ }^{1} \mathrm{H} \mathrm{NMR}$ ( $\delta$ in ppm from TMS in $\mathrm{C}_{5} \mathrm{D}_{5} \mathrm{~N}$ ) (Figure 3): 1.68-2.15 (br, 2H, backbone - $\underline{\mathrm{C}}_{2}-$ ), 2.64-2.98 (br, 1H, backbone - $\underline{\mathrm{CH}}-$ ), 4.93-5.35 (br, $2 \mathrm{H}$, - $\underline{\mathrm{H}}_{2}-$ ), 5.88-6.09 (br, 1H, furan H), 6.20-6.46 (br, 1H, furan $\mathrm{H})$.

Poly(5-methoxymethyl-2-vinylfuran) (PMMVF) was synthesized according to the same method as that for PHMVF, using MMVF $(0.201 \mathrm{~g}, 1.46 \mathrm{mmol})$ instead of HMVF, and a yellow solid was obtained. The yield was $0.089 \mathrm{~g}(44.5 \%)$. ${ }^{1} \mathrm{H}$ NMR ( $\delta$ in ppm from TMS in $\mathrm{C}_{5} \mathrm{D}_{5} \mathrm{~N}$ ) (Figure 3): 1.732.24 (br, 2H, backbone - $\underline{\mathrm{H}}_{2}-$ ), 2.59-2.80 (br, 1H, backbone

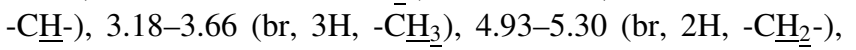
5.95-6.14 (br, $1 \mathrm{H}$, furan $\mathrm{H}-3$ ), $6.28-6.57$ (br, $1 \mathrm{H}$, furan $\mathrm{H}-4$ ). 
a) PHMVF
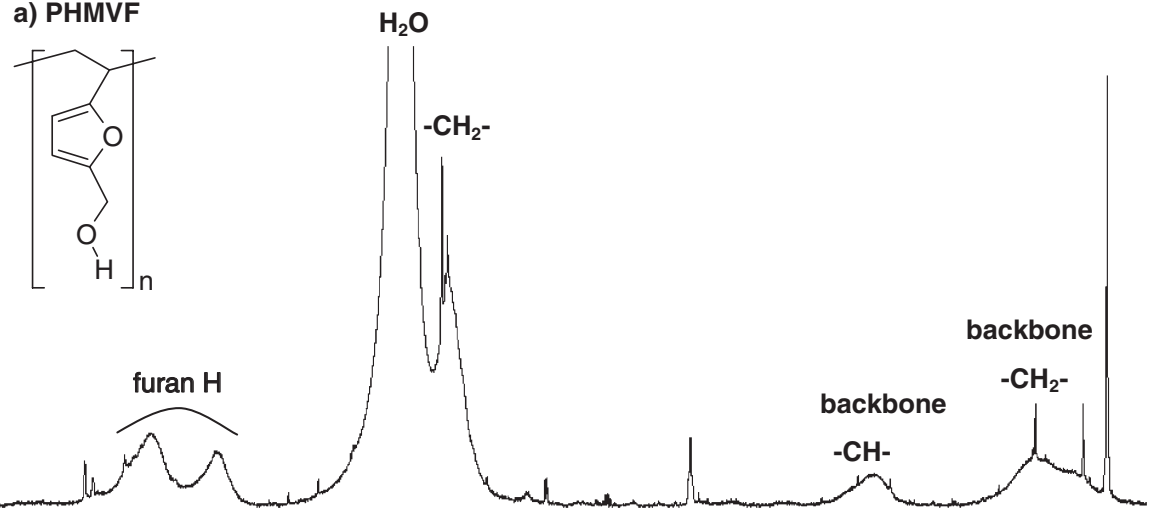

b) PMMVF
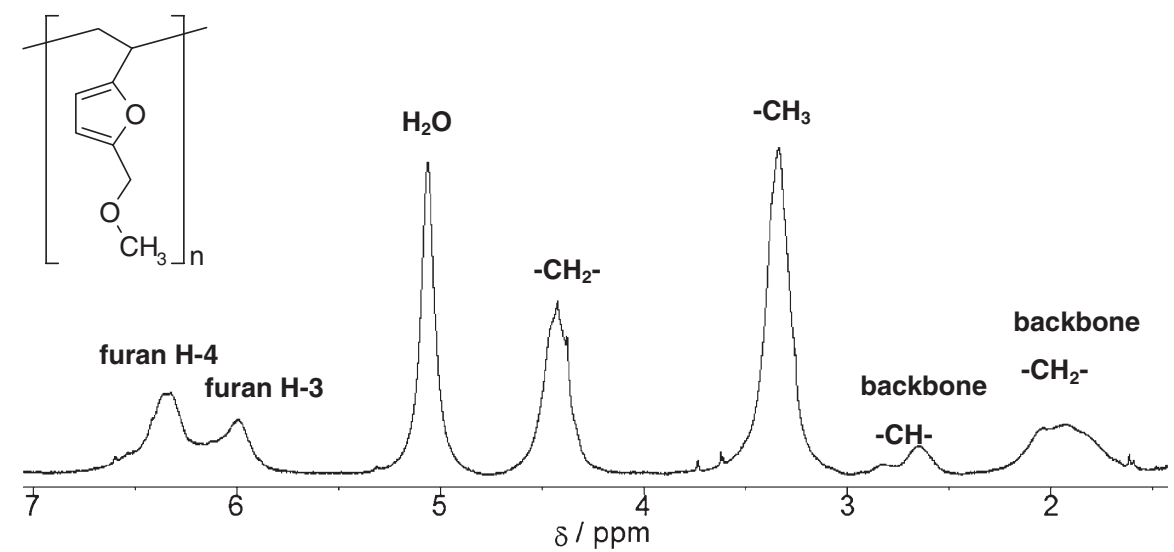

Figure 3. ${ }^{1} \mathrm{H}$ NMR spectra (pyridine- $\mathrm{d}_{5}, 600 \mathrm{MHz}$ ) of (a) PHMVF and (b) PMMVF.

\section{RESULTS AND DISCUSSION}

\section{Monomer Preparation}

The synthetic route for the novel biomass-based vinyl polymer is outlined in Scheme 1. Two novel polymers were synthesized from HMF along a similar route as that shown in the scheme with one slight difference, i.e., whether a methylation step was incorporated or not. To protect the reactive hydroxyl group before the Wittig reaction, we prepared MMF by methylating the hydroxyl group of HMF while refluxing HMF in a methanol solution that included $p$-toluene sulphonic acid. After the solvent was removed by evaporation, the mixture was refluxed again in water to decompose the acetal, created during the methylation step at the site of the formyl group, back into the formyl group again. The structure of the molecule was confirmed by ${ }^{1} \mathrm{H}$ and ${ }^{13} \mathrm{C}$ NMR spectroscopy. ${ }^{22}$

The compounds, HMF and MMF, were then subjected to the Wittig reaction, according to the method described in the experimental section. Since the conventional procedure for the Wittig reaction ${ }^{23}$ with HMF and furfural has not successfully produced corresponding vinyl molecules, leading to the predominant occurrence of the Cannizzaro reaction, ${ }^{24}$ another approach called the "solid-liquid phase transfer process" was examined. ${ }^{20}$ The reaction in the process was assumed to be promoted at the interface between the solid (potassium carbonate) and the liquid (dissolved phosphonium salt), and reportedly the conversion of furfural into 2-vinylfuran was achieved successfully. The products obtained with the reaction were structurally examined by using ${ }^{1} \mathrm{H}$ and ${ }^{13} \mathrm{C}$ NMR spectroscopy (Figure $1 \&$ Figure 2) together with 2D measurement such as C-H COSY and C-H COLOC, and we found them to be objective vinyl monomers, i.e., HMVF and MMVF. A small amount of contaminants (ethyl acetate and 1,4-dioxane) were observed in the spectra for HMVF (Figure 1), but not for MMVF (Figure 2). As far as we know, this is the first report describing a method of preparing HMVF and MMVF directly from corresponding aldehydes, i.e., HMF and MMF, and conversion was achieved regardless of whether the molecules had an unprotected hydroxyl group or not.

\section{Polymerization}

Free radical polymerization of the monomers, HMVF and MMVF, was examined separately using AIBN as an initiator in a bulk polymerization process. After the prescribed duration for polymerization, methanol was added to precipitate yellow polymeric materials in each case. The polymeric products had 
a) PHMVF

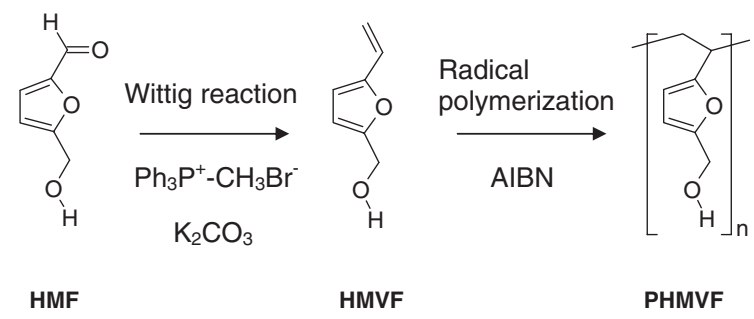

b) PMMVF

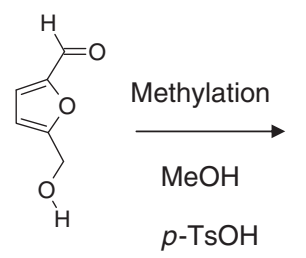

HMF

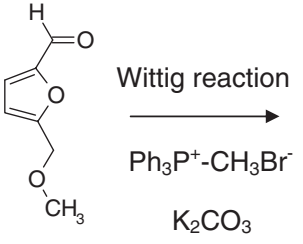

MMF

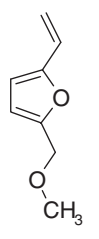

MMVF

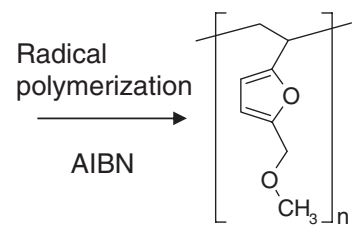

PMMVF

Scheme 1. Synthetic routes of (a) PHMVF and (b) PMMVF.

Table I. Number-average molecular weights $\left(M_{\mathrm{n}}\right)$ and molecular weight distributions $\left(M_{\mathrm{w}} / M_{\mathrm{n}}\right)$ of PHMVF and PMMVF

\begin{tabular}{ccc}
\hline Polymer & $M_{\mathrm{n}}$ & $M_{\mathrm{w}} / M_{\mathrm{n}}$ \\
\hline PHMVF & 2,170 & 1.35 \\
PMMVF & 2,890 & 1.33 \\
\hline
\end{tabular}

little difference in their solubility to the organic solvents. In fact, both polymers had good solubility in pyridine, but were poorly dissolved in chloroform or other polar aprotic solvents i.e., 1-methyl-2-pyrrolidone (NMP), N,N-dimethylformamide (DMF), dimethylsulfoxide (DMSO), and $N, N$-dimethylacetamide (DMAc). Moreover, they were found to be insoluble in many ordinary organic solvents such as tetrahydrofuran (THF), hexane, and methanol.

The chemical structures of the products were characterized by ${ }^{1} \mathrm{H}$ NMR as shown in Figure 3. Characteristic signals that were assigned to the vinyl group completely disappeared in the spectra. Instead, signals that were assigned to methine and methylene protons in the backbone appeared. It should be noted that radical polymerization proceeded bearing polymer molecules.

We estimated the number-average molecular weights $\left(M_{\mathrm{n}}\right)$ and molecular weight distributions $\left(M_{\mathrm{w}} / M_{\mathrm{n}}\right)$ of the products (PHMVF and PMMVF) by GPC, and these are listed in Table I. The products obtained were proved to be polymeric materials with small molecular-weight distributions, although the $M_{\mathrm{n}}$ of both polymers were relatively low. To obtain higher molecular-weight polymers, further efforts to adjust the feed ratio of AIBN to monomers, reaction time, and temperature may be required. However, this is the first paper reporting the synthesis of vinyl polymers, poly(5-hydroxymethyl-2-vinylfuran) (PHMVF) and poly(5-methoxymethyl-2-vinylfuran) (PMMVF), from 5-hydroxymethylfurfural (HMF).

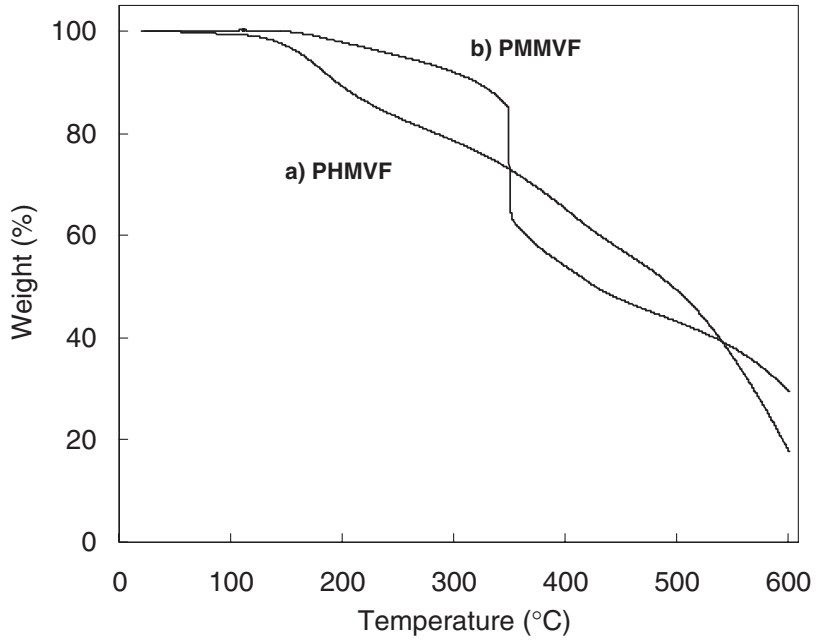

Figure 4. TGA curves of (a) PHMVF and (b) PMMVF. Heating rate was $10^{\circ} \mathrm{C} \mathrm{min}^{-1}$.

\section{Thermal Properties}

The thermal properties of the obtained polymers were investigated by means of TGA and DSC. Figure 4 shows the TGA curves of the polymers, PHMVF and PMMVF, with a heating rate of $10^{\circ} \mathrm{C} \mathrm{min}^{-1}$ under a helium gas atmosphere. It indicates that the introduction of the methyl group resulted in different decomposition patterns. The weight of PHMVF decreased slowly from a temperature of around $160^{\circ} \mathrm{C}$. That of PMMVF, on the other hand, decreased drastically when the temperature reached $350{ }^{\circ} \mathrm{C}$, presumably due to the decomposition. Although the thermal decomposition temperatures $\left(T_{\mathrm{d}}\right)$ of these polymers proved to be lower than that for the polystyrene at $363{ }^{\circ} \mathrm{C}$ in a previous paper, ${ }^{25}$ the residual weights of both polymers were nearly $50 \%$ after heating them 


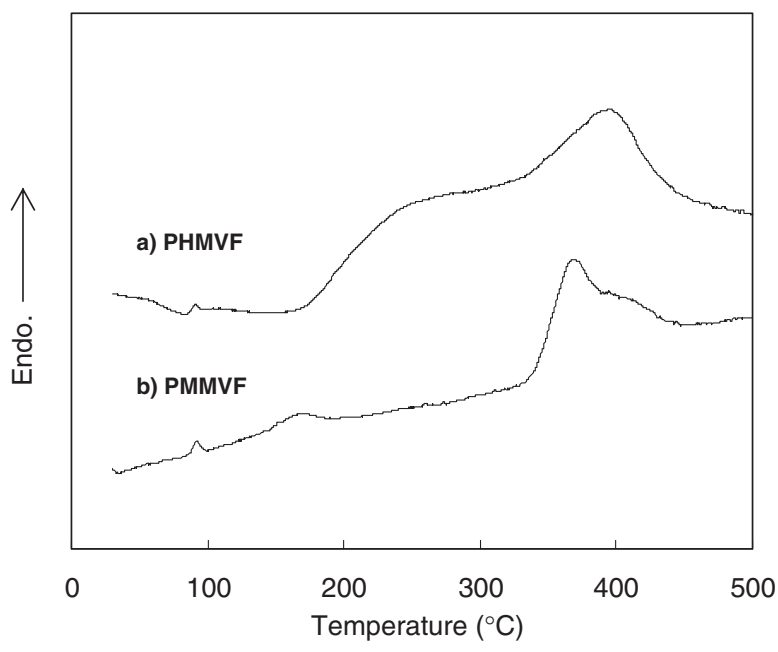

Figure 5. DSC curves of (a) PHMVF and (b) PMMVF. Heating rate was

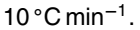

to $500{ }^{\circ} \mathrm{C}$, suggesting relatively small degradation rate for both polymers probably due to their furan rings.

Figure 5 shows the results of DSC measurements of PHMVF and PMMVF with a heating rate of $10^{\circ} \mathrm{C} \mathrm{min}^{-1}$ under a helium gas atmosphere. No glass transition phenomena are obviously apparent in the DSC curves. The peaks at around $91{ }^{\circ} \mathrm{C}$ in both thermograms (top and bottom) may correspond to the evaporation of absorbed moisture, and the other broad endothermic peaks seem to be caused by degradation. No clear peaks indicating melting point $\left(T_{\mathrm{m}}\right)$ or crystallization $\left(T_{\mathrm{c}}\right)$ are observed, suggesting the polymers obtained were not crystalline.

Further studies are necessary to investigate the properties of these brand-new biomass-based polymers.

\section{CONCLUSION}

We synthesized novel biomass-based vinyl polymers from HMF as the starting material. HMF and its methylated derivative (MMF) were efficiently converted to their vinyl derivatives by the Wittig reaction in a solid-liquid phase transfer process. Moreover, the resulting vinyl monomers were efficiently polymerized by radical polymerization in a bulk polymerization process. This is the first paper describing the synthesis of vinyl polymers from HMF or its methylated derivative (MMF).

Received: July 24, 2008

Accepted: September 2, 2008

Published: October 16, 2008

\section{REFERENCES}

1. A. J. Ragauskas, C. K. Williams, B. H. Davison, G. Britovsek, J. Cairney, C. A. Eckert, W. J. Frederick, Jr., J. P. Hallett, D. J. Leak, C. L. Liotta, J. R. Mielenz, R. Murphy, R. Templer, and T. Tschaplinski, Science, 311, 484 (2006).

2. C. Watkins, Inform, 18, 575 (2007).

3. K. Seri, Y. Inoue, and H. Ishida, Chem. Lett., 22 (2000).

4. C. Lansalot-Matras and C. Moreau, Catal. Commun., 4, 517 (2003).

5. C. Moreau, A. Finiels, and L. Vanoye, J. Mol. Catal. A: Chem., 253, 165 (2006).

6. Y. Roman-Leshkov, J. N. Chheda, and J. A. Dumesic, Science, $\mathbf{3 1 2}$ 1933 (2006).

7. Y. Román-Leshkov, C. J. Barrett, Z. Y. Liu, and J. A. Dumesic, Nature, 447, 982 (2007).

8. H. Zhao, J. E. Holladay, H. Brown, and Z. C. Zhang, Science, 316, 1597 (2007).

9. A. Gandini, American Chemical Society, 195 (1990).

10. F. W. Lichtenthaler, Carbohydr. Res., 313, 69 (1998).

11. M. Kröger, U. Prüße, and K.-D. Verlop, Top. Catal., 13, 237 (2000).

12. H. Hirai, J. Macromol. Sci. Chem., 21, 1165 (1984).

13. J. A. Moore and J. E. Kelly, J. Polym. Sci. Polym. Chem. Ed., 22, 863 (1984).

14. H. Koch and J. Pein, Polym. Bull., 13, 525 (1985).

15. A. Mitiakoudis and A. Gandini, Macromolecules, 24, 830 (1991).

16. M. N. Belgacem, J. Quillerou, and A. Gandini, Eur. Polym. J., 29, 1217 (1993).

17. S. Boufi, M. N. Belgacem, J. Quillerou, and A. Gandini, Macromolecules, 26, 6706 (1993).

18. K. Hatanaka, D. Yoshida, K. Okuyama, A. Miyagawa, K. Tamura, N. Sato, K. Hashimoto, M. Sagehashi, and A. Sakoda, Kobunshi Ronbunshu, 62, 316 (2005).

19. S. Abid, S. Matoussi, R. E. Gharbi, and A. Gandini, Polym. Bull., 57, 43 (2006).

20. J. Arekion, M. Delmas, and A. Gaset, Biomass, 3, 59 (1983).

21. Merck \& Co., Inc., US Patent, 19570904 (1962).

22. F. Podesta, V. Fajardo, A. J. Freyer, and M. Shamma, Arch. Pharm. (Weinheim), 321, 949 (1988).

23. R. Greenwald, M. Chaykovsky, and E. J. Corey, J. Org. Chem., 28, 1128 (1963).

24. A. K. Sen Gupta, Tetrahedron Lett., 50, 5205 (1968).

25. B. A. Howell, Y. Cui, and D. B. Priddy, J. Therm. Anal. Caldorim., 76, 313 (2004). 